\title{
Efficacy and Safety of Peroral Endoscopic Myotomy in Achalasia Patients with Failed Previous Intervention: A Systematic Review and Meta-analysis
}

\author{
Shali Tan', Chunyu Zhong1, Yutang Ren², Xujuan Luo ${ }^{1}$, Jin Xu11, Xiangsheng Fu³, Yan Peng ${ }^{1}$, and Xiaowei Tang ${ }^{1}$ \\ ${ }^{1}$ Department of Gastroenterology, Affiliated Hospital of Southwest Medical University, Luzhou, ${ }^{2}$ Department of Gastroenterology, \\ Beijing Tsinghua Changgung Hospital, Tsinghua University School of Clinical Medicine, Beijing, and ${ }^{3}$ Department of Gastroenterology, \\ Affiliated Hospital of North Sichuan Medical College, Nanchong, China
}

\begin{abstract}
Article Info
Received July 9, 2019

Revised October 4, 2019

Accepted November 4, 2019

Published online July 6, 2020

Corresponding Author

\section{Xiaowei Tang}

ORCID https://orcid.org/0000-0001-9947-0720

E-mail solitude5834@hotmail.com
\end{abstract}

Shali Tan, Chunyu Zhong, and Yutang Ren contributed equally to this work as first authors.

\begin{abstract}
Peroral endoscopic myotomy (POEM) has emerged as a rescue treatment for recurrent or persistent achalasia after failed initial management. Therefore, we aimed to investigate the efficacy and safety of POEM in achalasia patients with failed previous intervention. We searched the MEDLINE, Embase, Cochrane, and PubMed databases using the queries "achalasia," "peroral endoscopic myotomy," and related terms in March 2019. Data on technical and clinical success, adverse events, Eckardt score and lower esophageal sphincter (LES) pressure were collected. The pooled event rates, mean differences (MDs) and risk ratios (RR) were calculated. A total of 15 studies with 2,276 achalasia patients were included. Overall, the pooled technical success, clinical success and adverse events rate of rescue POEM were $98.0 \%$ (95\% confidence interval [Cl], $96.6 \%$ to $98.8 \%), 90.8 \%(95 \% \mathrm{Cl}, 88.8 \%$ to $92.4 \%)$ and $10.3 \%(95 \% \mathrm{Cl}, 6.6 \%$ to $15.8 \%)$, respectively. Seven studies compared the clinical outcomes of POEM between previous failed treatment and the treatment naïve patients. The RR for technical success, clinical success, and adverse events were $1.00(95 \% \mathrm{Cl}, 0.98$ to 1.01$), 0.98(95 \% \mathrm{Cl}, 0.92$ to 1.04$)$, and $1.17(95 \% \mathrm{Cl}$, 0.78 to 1.76$)$, respectively. Overall, there was significant reduction in the pre- and post-Eckardt score (MD, 5.77; $p<0.001)$ and LES pressure (MD, $18.3 \mathrm{~mm} \mathrm{Hg} ; p<0.001)$ for achalasia patients with failed previous intervention after POEM. POEM appears to be a safe, effective and feasible treatment for individuals who have undergone previous failed intervention. It has similar outcomes in previously treated and treatment-naïve achalasia patients. (Gut Liver 2021;15:153-167)
\end{abstract}

Key Words: Esophageal achalasia; Meta-analysis; Pyloromyotomy; Safety; Treatment failure

\section{INTRODUCTION}

Achalasia is an esophageal motility disorder, caused by the absence of myenteric neurons and the subsequent impaired lower esophageal sphincter (LES) relaxation. Patients present with dysphagia, regurgitation, chest pain, and weight loss. ${ }^{1}$ Treatment options include Heller myotomy (HM), pneumatic balloon dilation (PBD), and botulinum toxin injection (BTI). Although HM is considered the first-line therapy due to its superior long-term outcomes, a failure rate of approximately $10 \%$ to $20 \%$ is observed. ${ }^{2,3}$ Similarly, despite a 90\% PBD success rate, recurrence of symptoms occurs post-procedure in $20 \%, 30 \%$, and $40 \%$ of patients in 2, 5 and 10 years, respectively. ${ }^{4-6}$ Lastly, BTI is safety and efficacious in the majority of patients; however, symptomatic relief is short term with only $29 \%$ of patients reporting continued success during intermediate followup. ${ }^{7}$ In cases of symptom recurrence after primary intervention, surgical myotomy is often technically challenging. Additionally, a high risk of adverse events is documented. Reported rates of gastrointestinal perforation range from $1.5 \%$ to $20 \%$ and are typically due to the formation of scars, fibrosis and adhesions resulting from previous surgical or endoscopic interventions. ${ }^{8-12}$ PBD and BTI are also rescue management strategies for recurrent achalasia. However, the durability of both interventions is limited. Repeat treat- 
ment for relapsing symptoms is required in up to $45 \%$ of patients after 2 years. ${ }^{5,13}$ Furthermore, previous myotomy is considered to be a relative contraindication to PBD. ${ }^{14,15} \mathrm{Re}$ cently, peroral endoscopic myotomy (POEM) has emerged as a treatment for recurrent or persistent achalasia after failed initial management. It can avoid shortcomings of other treatments mentioned above. Several studies have demonstrated a promising clinical success rate of greater than $90 \% .{ }^{16-30}$ However, some of these studies in this setting are limited by their small numbers. Therefore, the aim of this systematic review and meta-analysis was to determine the efficacy and safety of POEM as a therapy in those who have undergone failed endoscopic or surgical treatments. We also compared the efficacy and safety of POEM in patients who had previously failed endoscopic or surgical therapies with those who underwent the POEM as a primary treatment.

\section{METHODS}

\section{Search strategy and study selection}

Utilizing Preferred Reporting Items for Systematic Reviews and Meta-Analyses guidelines, ${ }^{31}$ the following databases were searched from interception to March 2019: MEDLINE, Embase, Cochrane, and PubMed. The keywords "achalasia," "esophageal achalasia," "peroral endoscopic myotomy," "per-oral endoscopic myotomy," "Heller myotomy," "POEM," "Pneumatic dilation," "HM," and the related terms provided in Supplementary Table 1 were used. The references of published articles were also manually reviewed to ensure the inclusion of all relevant studies. Articles published in the Chinese language were reviewed by coauthor X.T. However, none met our inclusion criteria. Two authors (S.T. and C.Z.) screened all titles, abstracts and full texts independently. Any discrepancies were discussed with a third investigator (X.T.).

\section{Eligibility criteria and data collection}

Two reviewers (X.F. and Y.R.) assessed the articles independently based on the predefined inclusion criteria and exclusion criteria. All prospective, retrospective, casecontrol and cohort studies and other clinical trials were included if they featured patients: (1) diagnosed with achalasia and (2) who had undergone POEM after failed previous treatment(s). Manuscripts were excluded if: (1) they described non-human studies, (2) were single-arm studies with treatment-naïve patients undergoing POEM or (3) were case-reports less than five patients, commentaries, reviews, editorials, conference abstracts or surveys. For overlapping publications from the same center, only the most recent and comprehensive publication was considered for inclusion.

Two reviewers (Y.P. and X.T.) collected the following data independently: baseline characteristics (author name, year of publication, country, study design, study duration, group, sample size, patient age, and sex distribution); clini-

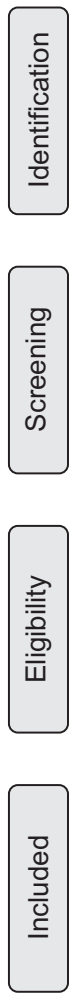

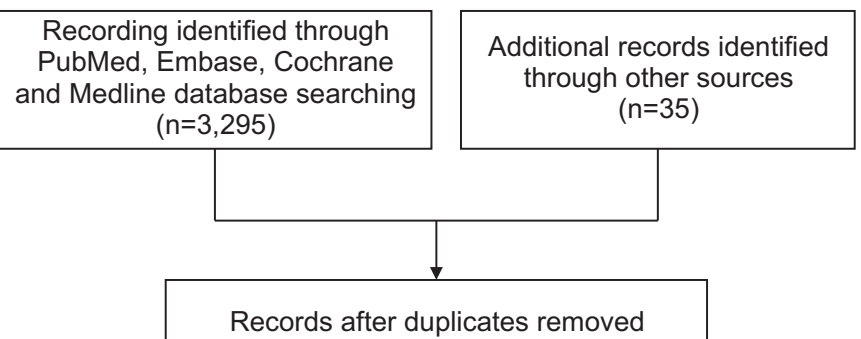

$(n=2,368)$

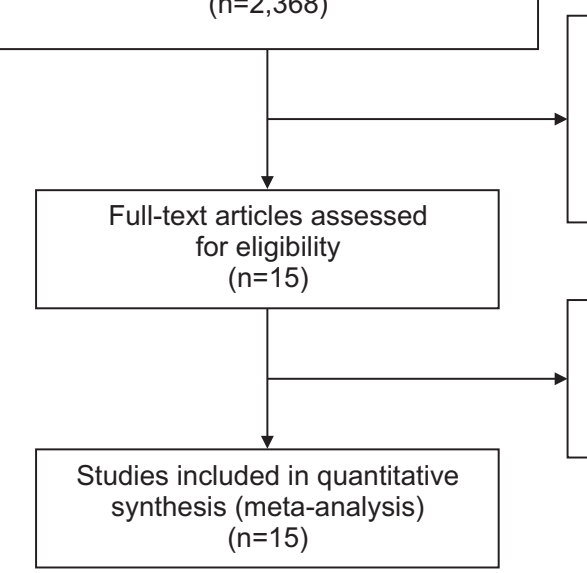

Full-text articles excluded with reasons overlapping publications, ongoing study

$(n=0)$

\section{Records excluded after reviewing title and abstract, with reasons case report, review, fewer than 5 patients, irrelevant $(n=2,353)$}

Fig. 1. Preferred Reporting Items for Systematic Reviews and MetaAnalyses flowchart. 
cal characteristics (initial achalasia treatment, achalasia subtype, myotomy orientation, myotomy length, procedure time, and length of hospital stay) and clinical outcomes (technical success, clinical success, incidence of symptomatic reflux and reflux esophagitis). Also, major and minor adverse events were recorded to determine the safety of POEM. Pre- and post-procedure Eckardt scores and LES pressures were also included.

\section{Quality assessment}

The Newcastle-Ottawa Quality Assessment Scale for non-randomized studies was used by two investigators (X.L. and J.X.) to assess the risk of bias in the included studies. ${ }^{32,33}$ This scale rates three study aspects: selection, comparability and outcome. The maximum attainable score is 9. Each study was rated as "high quality" (score $\geq 7$ ), "medium quality" (score of 5 or 6 ) or "low quality" (score $\leq 4)$.

\section{Endpoint definition and statistical analysis}

The primary outcomes were efficacy (as measured by technical and clinical success) and safety (indicated by presence and severity of adverse events) of POEM after failure of endoscopic or surgical intervention for achalasia. Technical success was defined as successful completion of the entire procedure. Clinical success was defined as an Eckardt score $\leq 3$ during the study follow-up period. Procedure-related and post-procedure adverse events were included. Adverse events were divided into major and minor according to the NOSCAR white paper. ${ }^{34}$ Major adverse events were defined as events requiring additional intervention during or after POEM including endoscopic or surgical interventions, bleeding requiring transfusion, readmission within 30 days, prolonged hospital stay $(>5$ days) and clinical inflammation. Air-related outcomes and fluid collections were considered to be major adverse events when requiring drainage. Adverse events which were managed conservatively were defined as minor adverse events. The secondary endpoints of the study were the mean reduction in Eckardt scores and LES pressures, the difference in procedure time and hospital stay between the patients with and without previous intervention(s), and gastroesophageal reflux disease (GERD) incidence during follow-up. All statistical analyses were conducted using Comprehensive Meta-Analysis version 2 (Biostat, Englewood, NJ, USA), Cochrane Review Manager 5.3 (London,

Table 1. Baseline Characteristics of Included Studies

\begin{tabular}{|c|c|c|c|c|c|c|c|}
\hline Author (year) & Country & Design & Duration & $\begin{array}{l}\text { No. of } \\
\text { patients }\end{array}$ & Group & Age, yr & $\begin{array}{c}\text { Male sex, } \\
\text { No. (\%) }\end{array}$ \\
\hline Tyberg et al. $(2016)^{16}$ & USA & Prospective & Mar 2014-Aug 2015 & 46 & 46 PTF & $49.3 \pm 16.78$ & $20(45.0)$ \\
\hline Tyberg et al. $(2018)^{21}$ & USA & Prospective & Jan 2012-Jan 2017 & 51 & 51 PTF & 54.2 & $24(47.0)$ \\
\hline Onimaru et al. $(2013)^{25}$ & Japan & Prospective & Sep 2008-Dec 2012 & 10 & 10 PTF & 52 & $5(50.0)$ \\
\hline Vigneswaran et al. $(2014)^{26}$ & USA & Prospective & Oct 2010-Jun 2013 & 5 & 5 PTF & 69.6 & $4(80.0)$ \\
\hline Zhou et al. $(2013)^{28}$ & China & Prospective & Mar 2011-Dec 2011 & 12 & $12 \mathrm{PTF}$ & 51.1 & $5(41.7)$ \\
\hline Ling et al. $(2014)^{17}$ & China & Prospective & May 2010-Sep 2012 & 51 & $\begin{array}{l}21 \text { PTF } \\
30 \text { Naïve }\end{array}$ & $\begin{array}{l}43.2 \pm 12.7 \\
42.5 \pm 11.3\end{array}$ & $\begin{array}{r}8(38.1) \\
10(33.3)\end{array}$ \\
\hline Ngamruengphong et al. $(2017)^{18}$ & USA & Retrospective & Dec 2009-Sep 2015 & 180 & $\begin{array}{l}90 \text { PTF with } \mathrm{HM} \\
90 \text { PTF without } \mathrm{HM}\end{array}$ & $\begin{array}{l}54 \pm 15 \\
53 \pm 14\end{array}$ & $\begin{array}{l}44(48.9) \\
38(42.2)\end{array}$ \\
\hline Tang et al. $(2017)^{19}$ & China & Retrospective & Jul 2011-Jan 2014 & 61 & $\begin{array}{l}22 \text { PTF } \\
39 \text { Naïve }\end{array}$ & $\begin{array}{l}34.9 \pm 7.7 \\
38.5 \pm 11.3\end{array}$ & $\begin{array}{l}14(63.6) \\
20(51.3)\end{array}$ \\
\hline Kristensen et al. $(2017)^{20}$ & Denmark & Retrospective & Jan 2012-May 2016 & 66 & $\begin{array}{l}14 \mathrm{PTF} \text { with } \mathrm{HM} \\
52 \mathrm{PTF} \text { without } \mathrm{HM}\end{array}$ & $\begin{array}{l}43.5(22-75) \\
49.5(18-77)\end{array}$ & $\begin{array}{r}7(50.0) \\
26(50.0)\end{array}$ \\
\hline Orenstein et al. $(2015)^{23}$ & USA & Retrospective & May 2011-Sep 2013 & 40 & $\begin{array}{l}16 \text { PTF } \\
24 \text { Naïve }\end{array}$ & $\begin{array}{l}\text { NA } \\
\text { NA }\end{array}$ & $\begin{array}{l}\text { NA } \\
\text { NA }\end{array}$ \\
\hline Nabi et al. $(2018)^{24}$ & India & Retrospective & Jan 2013-Nov 2016 & 502 & $\begin{array}{l}242 \text { PTF } \\
260 \text { Naïve }\end{array}$ & $\begin{array}{l}42.4 \pm 13.6 \\
38.0 \pm 13.6\end{array}$ & $\begin{array}{l}137(56.6) \\
142(54.6)\end{array}$ \\
\hline Sharata et al. $(2013)^{27}$ & USA & Retrospective & Oct 2010-May 2012 & 40 & $\begin{array}{l}12 \text { PTF } \\
28 \text { Naïve }\end{array}$ & $\begin{array}{l}55 \pm 17 \\
48 \pm 21\end{array}$ & $\begin{array}{r}5(41.7) \\
12(42.9)\end{array}$ \\
\hline Zhang et al. $(2018)^{22}$ & USA & Retrospective & Oct 2009-Oct 2016 & 318 & $\begin{array}{l}46 \mathrm{PTF}^{*} \\
272 \mathrm{PTF}^{+}\end{array}$ & $\begin{array}{l}55(17-85) \\
54(10-94)\end{array}$ & $\begin{array}{r}24(52.2) \\
155(57.0)\end{array}$ \\
\hline Jones et al. $(2015)^{29}$ & USA & Retrospective & Aug 2012-Oct 2014 & 45 & $\begin{array}{l}15 \text { PTF } \\
30 \text { Naïve }\end{array}$ & $\begin{array}{l}64.4 \pm 12 \\
46.2 \pm 17.2\end{array}$ & $\begin{array}{r}3(20.0) \\
25(83.3)\end{array}$ \\
\hline Liu et al. $(2019)^{30}$ & China & Retrospective & Aug 2010-Dec 2014 & 849 & $\begin{array}{l}245 \text { PTF } \\
604 \text { Naïve }\end{array}$ & $\begin{array}{l}38(6-98) \\
38(8-77)\end{array}$ & $\begin{array}{l}132(53.9) \\
291(48.2)\end{array}$ \\
\hline
\end{tabular}

Data are presented as mean \pm SD or median (range).

PTF, previous treatment failure; HM, Heller myotomy.

*Previous surgical and endoscopic treatment failure; ${ }^{\dagger}$ Previous endoscopic treatment failure. 


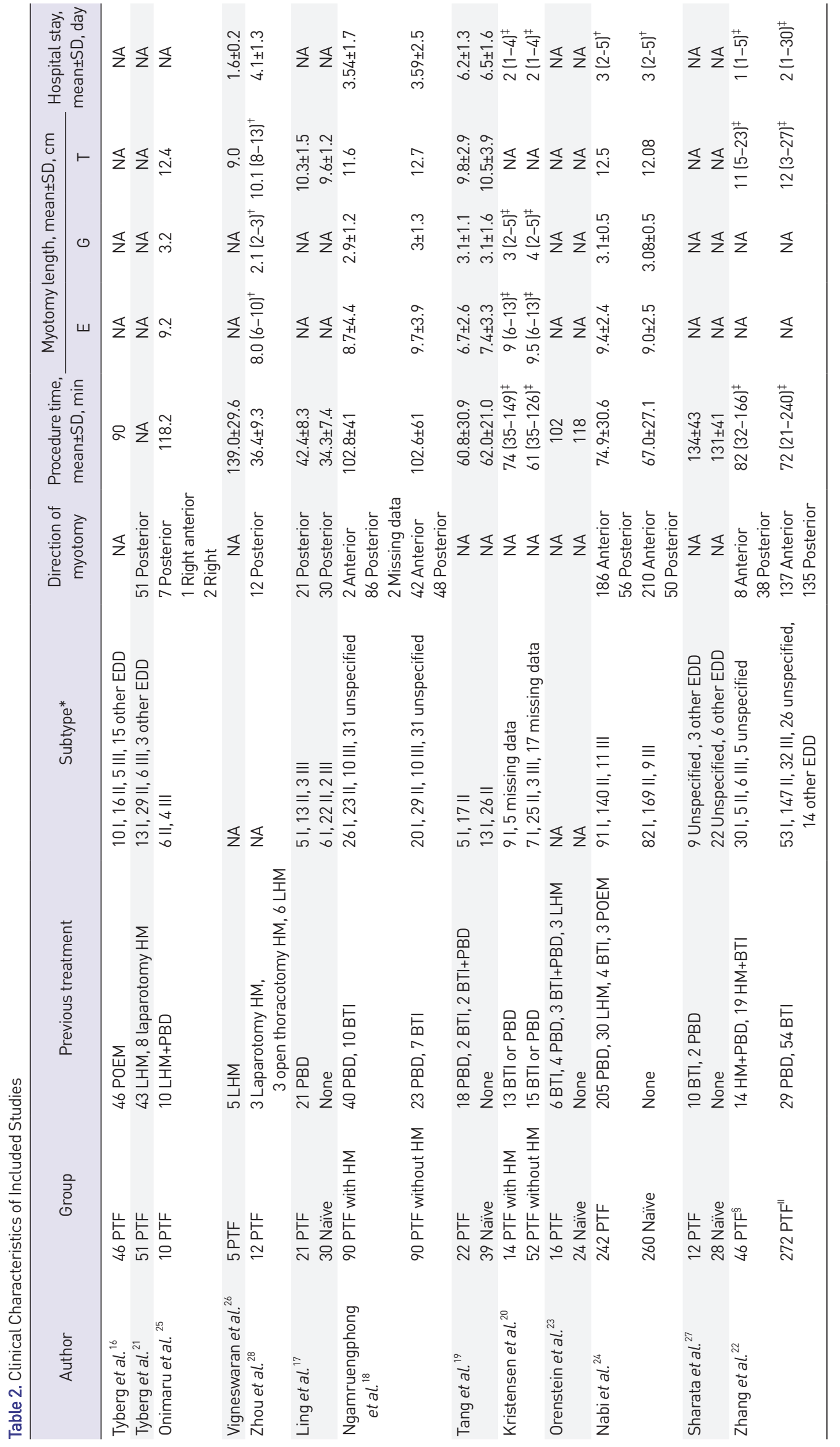




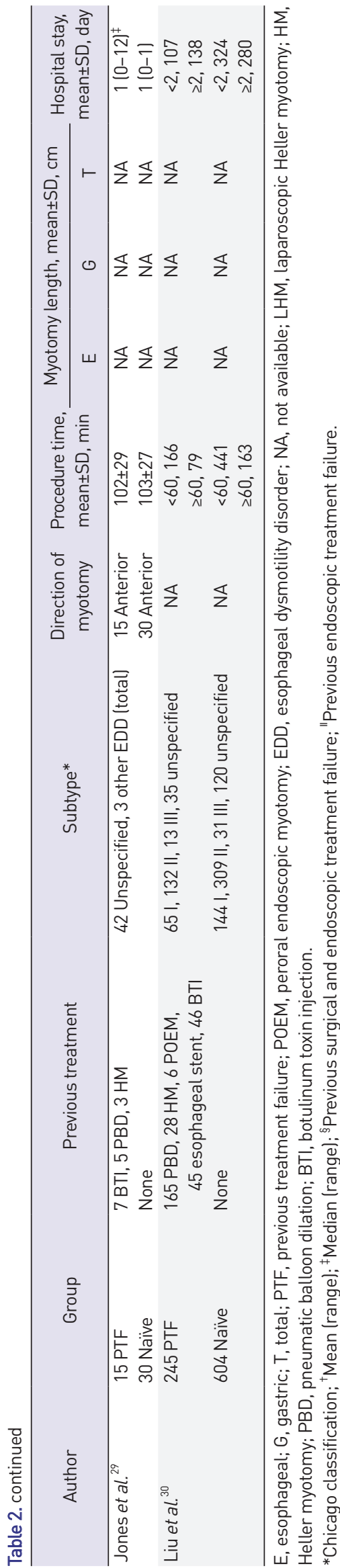

UK) and GraphPad Prism version 5.00 (San Diego, CA, USA). Pooled effects with $95 \%$ confidence intervals (CI) were calculated for technical success, clinical success and adverse events. The mean difference (MD) was calculated for Eckardt score, LES pressure, procedure time and length of hospital stay. We also compared the efficacy and safety of POEM in patients who had previously failed endoscopic or surgical therapies with those who underwent POEM as a primary treatment for achalasia. Risk ratios (RR) were derived for technical success, clinical success and adverse events. The heterogeneity between the studies was assessed using the $\mathrm{I}^{2}$ test and Cochran's $\mathrm{Q}$ statistic in which a $\mathrm{p}<0.1$ indicates substantial heterogeneity. $\mathrm{I}^{2}$ values of around $25 \%, 50 \%$ and $75 \%$ were considered as low, moderate and high heterogeneity, respectively. When $\mathrm{I}^{2}$ was greater than $50 \%$ and/or the Cochran's $\mathrm{Q}$ test provided a $\mathrm{p}<0.1$, we ran analyses with the random-effect model, otherwise we used the fixed-effect model. Publication bias was assessed using funnel plots and the Egger's regression test. In addition, we performed subgroup analyses according to follow-up time and adverse events (major and minor adverse events), and a sensitivity analysis to confirm whether a single study caused an effect. A two-sided $\mathrm{p}<0.05$ was regarded as statistically significant.

\section{RESULTS}

\section{Study characteristics and quality}

Using the search strategy, 3,330 records were identified. After exclusion criteria, 15 studies were eligible (Fig. 1). The baseline characteristics of the included studies are summarized in Table 1 . The 15 studies were all conducted between September 2008 and January 2017. Three multicenter studies, all lead by USA investigators, were included. The 12 single-center studies were conducted in Japan $(n=1)$, USA $(n=5)$, China $(n=4)$, Denmark $(n=1)$, and India $(n=1)$. Among these studies, six were prospective. No randomized control trials met inclusion criteria.

A total of 2,276 patients were included in our study. One thousand-fifteen were treatment-naïve and 1,261 patients had undergone previous treatment(s) for achalasia. The mean ages of patients ranged from 34.9 to 69.6 years. Overall, five studies were single arm studies with failed endoscopic or/and surgical interventions. Seven studies compared the clinical outcomes of POEM between previous failed treatment and the treatment naive patients.

Table 2 shows the clinical characteristics of the included studies. Information on achalasia subtype was available for 2,197 patients (type I $\mathrm{n}=579$, type II $\mathrm{n}=1,108$, type III $\mathrm{n}=145$, and unspecified type $\mathrm{n}=321$ ). There were $44 \mathrm{pa}$ - 
tients with other esophageal dysmotility disorders. Submucosal myotomies $(534 / 1,169 ; 45.7 \%)$ were posterior. The mean procedure time, total myotomy length and hospital stay ranged from 36.4 to 139 minutes, 9.0 to $12.7 \mathrm{~cm}$ and 1 to 6.2 days, respectively. The assessment of risk of bias of individual studies is shown in the Table 3. Follow-up time ranged from 5 to 28 months (Table 4).

\section{Technical success}

Thirteen studies with 1,179 patients reported the technical success of POEM for patients with prior endoscopic or/and surgical treatment. Technical success ranged from $97.1 \%$ to $100 \%$ and was achieved in 1,170 (99.2\%) patients (Table 4). Pooled technical success was 98.0\% (95\% CI, $96.6 \%$ to $98.8 \%$ ) with no statistically significant heterogeneity $\left(\mathrm{Q}=9.99, \mathrm{p}=0.62, \mathrm{I}^{2}=0 \%\right)$ (Fig. 2A). Sensitivity analysis was performed removing one study at a time, and confirmed the same outcomes of the main analyses. There was no publication bias amongst the studies as shown in the Supplementary Fig. 1A (Egger's regression test $\mathrm{p}=0.38$ ).

\section{Clinical success}

Ten studies with 1,095 patients reported the clinical success of POEM for patients with prior endoscopic or/ and surgical treatment. Clinical success ranged from $81 \%$ to $100 \%$ in these studies. Clinical success was achieved in 999 patients $(91.2 \%)$ at 3-month follow-up (Table 4). The pooled clinical success in patients with greater than three months' follow-up was $90.8 \%$ (95\% CI, $88.8 \%$ to $92.4 \%$ ) with a low degree of heterogeneity $(\mathrm{Q}=10.73, \mathrm{p}=0.29$, $\left.\mathrm{I}^{2}=16.14 \%\right)$ as shown in Fig. $2 \mathrm{~B}$. Subgroup analysis was undertaken on the basis of duration of follow-up. Four studies reported clinical success with 1-year follow-up. Two studies reported 2- and 3-year follow-ups. The pooled results of clinical success rates for 1-, 2-, and 3-year followups were $89.9 \%$ (95\% CI, $86.9 \%$ to $92.3 \%$ ), $85.8 \%$ (95\% CI, $81.7 \%$ to $89.1 \%$ ) and $81.2 \%$ (95\% CI, $76.2 \%$ to $85.4 \%$ ), respectively (Supplementary Fig. 2). Sensitivity analysis removing one study at a time was performed and confirmed the outcomes of the main analyses. However, when removing either the study by Zhang et al..$^{22}$ or Ngamruengphong et al., ${ }^{18}$ a considerable reduction in heterogeneity occurred, changing the $\mathrm{I}^{2}$ from $16.14 \%$ to $0 \%$. There was no publication bias amongst the studies as shown in Supplementary Fig. 1B (Egger' s regression test $\mathrm{p}=0.49$ ).

\section{Adverse events}

Fourteen studies with 1,195 patients reported the adverse events of POEM for patients with prior endoscopic or/and surgical treatment. A total of 83 (6.9\%) adverse events occurred (Table 5). The pooled adverse events rate was 10.3\% ( $95 \%$ CI, $6.6 \%$ to $15.8 \%$ ) with a high degree of heterogeneity $\left(\mathrm{Q}=45.67, \mathrm{p}<0.001, \mathrm{I}^{2}=71.54 \%\right)$, as shown in Fig. 2C. The pooled major and minor adverse events rates were $6.4 \%$ ( $95 \%$ CI, $3.6 \%$ to $11.1 \%$ ) and $7.0 \%$ (95\% CI, $5.2 \%$ to $9.5 \%$ ) as shown in Supplementary Fig. 3. Sensitivity analysis demonstrated that the largest change occurred when the study conducted by Zhang et al. ${ }^{22}$ was removed. The heterogeneity decreased from $71.54 \%$ to $60.74 \%$. The effect sized changed from $10.3 \%$ to $11.8 \%$ (95\% CI, $7.9 \%$ to $17.3 \%$ ). There was no publication bias amongst the studies as shown in Supplementary Fig. 1C (Egger's regression test $\mathrm{p}=0.39$ ).

Table 3. Newcastle-Ottawa Quality Assessment Scale for Included Studies

\begin{tabular}{|c|c|c|c|c|c|c|c|c|c|c|}
\hline \multirow{2}{*}{ Study } & \multicolumn{4}{|c|}{ Selection } & \multicolumn{3}{|c|}{ Outcome assessment } & \multicolumn{2}{|c|}{ Comparability } & \multirow{2}{*}{ Quality of study } \\
\hline & 1 & 2 & 3 & 4 & 1 & 2 & 3 & 1 & 2 & \\
\hline Tyberg et al. ${ }^{16}$ & + & & + & + & + & + & + & & & Medium quality \\
\hline Ling et al. ${ }^{17}$ & + & & + & + & + & + & + & + & + & High quality \\
\hline Tang et al. ${ }^{19}$ & + & + & + & + & + & + & + & + & + & High quality \\
\hline Ngamruengphong et al. ${ }^{18}$ & + & + & + & + & + & + & + & + & & High quality \\
\hline Kristensen et al. ${ }^{20}$ & + & + & + & + & + & + & + & & + & High quality \\
\hline Tyberg et al. ${ }^{21}$ & + & & + & + & + & + & + & & & Medium quality \\
\hline Orenstein et al. ${ }^{23}$ & + & + & + & + & + & + & + & & & High quality \\
\hline Nabi et al. ${ }^{24}$ & + & + & + & + & + & + & + & + & & High quality \\
\hline Onimaru et al. ${ }^{25}$ & + & & + & + & + & + & + & & & Medium quality \\
\hline Vigneswaran et al. ${ }^{26}$ & & & + & + & + & + & + & & & Medium quality \\
\hline Sharata et al. ${ }^{27}$ & + & + & + & + & + & + & + & + & + & High quality \\
\hline Zhang et al. ${ }^{22}$ & + & + & + & + & + & + & + & & + & High quality \\
\hline Zhou et al. ${ }^{28}$ & + & & + & + & + & + & + & & & Medium quality \\
\hline Jones et al. ${ }^{29}$ & + & + & + & + & + & + & + & & + & High quality \\
\hline Liu et al. ${ }^{30}$ & + & + & + & + & + & + & + & & + & High quality \\
\hline
\end{tabular}

Selection: 1, representativeness of the exposed cohort; 2, selection of the nonexposed cohort; 3 , ascertainment of exposure; 4, outcome of interest not present at start of study. Outcome assessment: 1, assessment of outcome; 2, adequacy of duration of follow-up; 3 , adequacy of completeness of follow-up. Comparability: 1, study controls for confounder; 2 , study controls for any additional factors. 
Table 4. Clinical Outcomes of Included Studies during Follow-up

\begin{tabular}{|c|c|c|c|c|c|}
\hline \multirow[b]{2}{*}{ Author } & \multirow[b]{2}{*}{ Group } & \multicolumn{3}{|c|}{$\%$ (No./No.) } & \multirow{2}{*}{$\begin{array}{l}\text { Follow-up, } \\
\text { mean (range), } \\
\text { mo }\end{array}$} \\
\hline & & $\begin{array}{l}\text { Technical } \\
\text { success }\end{array}$ & Clinical success & $\begin{array}{l}\text { Symptomatic reflux and } \\
\text { reflux esophagitis }\end{array}$ & \\
\hline Tyberg et al. ${ }^{16}$ & 46 PTF & $100(46 / 46)$ & $85(41 / 46)(3-m o ~ F U)$ & NA & $12.2(1-32)$ \\
\hline Tyberg et al. ${ }^{21}$ & 51 PTF & $100(51 / 51)$ & $94(48 / 51)(1-y r$ FU) & NA & $24.4(12-52)$ \\
\hline Onimaru et al. ${ }^{25}$ & 10 PTF & $100(10 / 10)$ & NA & NA & 18.3 \\
\hline Vigneswaran et al. ${ }^{26}$ & ${ }^{6} 5$ PTF & $100(5 / 5)$ & NA & NA & 4.9 \\
\hline Zhou et al. ${ }^{28}$ & $12 \mathrm{PTF}$ & $100(12 / 12)$ & $91.7(11 / 12)(5-14 \mathrm{mo} \mathrm{FU})$ & Reflux esophagitis $8.3(1 / 12)$ & $10.4(5-14)$ \\
\hline \multirow[t]{2}{*}{ Ling et al. ${ }^{17}$} & 21 PTF & $100(21 / 21)$ & $\begin{array}{l}92.3(19 / 21) \text { (postoperative), } \\
87.5(18 / 21) 1-y r \text { FU }\end{array}$ & Reflux esophagitis 19.0 (4/21) & 13.2 \\
\hline & 30 Naïve & $100(30 / 30)$ & NA & NA & 14.4 \\
\hline \multirow[t]{2}{*}{$\begin{array}{l}\text { Ngamruengphong } \\
\text { et al. }{ }^{18}\end{array}$} & 90 PTF (with HM) & $98(88 / 90)$ & $81.2(69 / 85)$ & $\begin{array}{l}\text { Symptomatic reflux } 30 \text { (21/70) } \\
\text { Reflux esophagitis } 44 \text { (18/41) }\end{array}$ & $9(4-14)^{*}$ \\
\hline & 90 PTF (without HM) & $100(90 / 90)$ & $\begin{array}{c}94.8 \text { (77/82) (total } n=167) \\
(\geq 3-\mathrm{mo} \mathrm{FU)}\end{array}$ & $\begin{array}{l}\text { Symptomatic reflux } 32 \text { (24/76) } \\
\text { Reflux esophagitis } 52 \text { (23/44) }\end{array}$ & $8.5(1.3-18.5)^{*}$ \\
\hline \multirow[t]{2}{*}{ Tang et al. ${ }^{19}$} & $22 \mathrm{PTF}$ & $100(22 / 22)$ & $95.5(21 / 22)$ & Reflux esophagitis $23.5(4 / 17)$ & 12 \\
\hline & 39 Naïve & $100(39 / 39)$ & 92.3 (36/39) (1-yr FU) & Reflux esophagitis 20 (7/35) & 12 \\
\hline \multirow[t]{2}{*}{ Kristensen et al. ${ }^{20}$} & 14 PTF (with HM) & NA & NA & NA & 24 \\
\hline & 52 PTF (without HM) & NA & NA & NA & 24 \\
\hline \multirow[t]{2}{*}{ Orenstein et al. ${ }^{23}$} & 16 PTF & NA & NA & NA & 9.0 \\
\hline & 24 Naïve & NA & NA & NA & 10.1 \\
\hline \multirow[t]{2}{*}{ Nabi et al. ${ }^{24}$} & 242 PTF & $97.1(235 / 242)$ & $\begin{array}{l}92.5(186 / 201)(6-\mathrm{mo} F U) \\
91.2(145 / 159)(1-\mathrm{yr} \text { FU) } \\
84.2(85 / 101)(2-\mathrm{yr} \text { FU) } \\
76.3(29 / 38)(3-\mathrm{yr} \text { FU) }\end{array}$ & $\begin{array}{l}\text { Symptomatic reflux } 17.8(26 / 146) \\
\text { Reflux esophagitis } 20.7(24 / 116)\end{array}$ & $20(1-45)^{+}$ \\
\hline & 260 Naïve & $98.1(255 / 260)$ & $\begin{array}{l}92.4(206 / 223)(6-m o \text { FU) } \\
90.7(166 / 183)(1-y r \text { FU) } \\
87.5(112 / 128)(2-y r \text { FU) } \\
87.1(27 / 31)(3-y r \text { FU) }\end{array}$ & $\begin{array}{l}\text { Symptomatic reflux } 16.4 \text { (22/134) } \\
\text { Reflux esophagitis } 22.1(29 / 131)\end{array}$ & $20(1-45)^{+}$ \\
\hline \multirow[t]{2}{*}{ Sharata et al. ${ }^{27}$} & $12 \mathrm{PTF}$ & $100(12 / 12)$ & $100(12 / 12)$ & NA & 6 \\
\hline & 28 Naïve & $100(28 / 28)$ & 100 (28/28) (postoperative) & NA & 6 \\
\hline \multirow[t]{2}{*}{ Zhang et al. ${ }^{22}$} & $46 \mathrm{PTF}^{\ddagger}$ & $100(46 / 46)$ & $95.7(44 / 46)$ & Reflux esophagitis $46.2(12 / 26)$ & $28(3-46)^{+}$ \\
\hline & $272 \mathrm{PTF}^{\S}$ & $100(272 / 272)$ & $95.1(255 / 272)(>3 \mathrm{mo})$ & Reflux esophagitis $34.0(50 / 147)$ & $23(3-78)^{+}$ \\
\hline \multirow[t]{2}{*}{ Jones et al. ${ }^{29}$} & 15 PTF & $100(15 / 15)$ & NA & NA & $12^{+}$ \\
\hline & 30 Naïve & $100(30 / 30)$ & NA & NA & $10^{+}$ \\
\hline \multirow[t]{2}{*}{ Liu et al. ${ }^{30}$} & 245 PTF & $100(245 / 245)$ & $\begin{array}{r}88.6(217 / 245)(1-y r \text { FU) } \\
86.5(212 / 245)(2-y r \text { FU) } \\
82(201 / 245)(5-y r \text { FU) }\end{array}$ & $\begin{array}{l}\text { Symptomatic reflux } 18.8 \text { (46/245) } \\
\text { Reflux esophagitis } 22.8 \text { (46/202) } \\
\text { Symptomatic reflux } 14.7 \text { (89/604) }\end{array}$ & $23(1-71)^{+}$ \\
\hline & 604 Naïve & $100(604 / 604)$ & $\begin{array}{l}95.0(574 / 604)(1-y r \text { FU) } \\
93.5(565 / 604)(2-y r \text { FU) } \\
91.7(554 / 604)(5-y r \text { FU) }\end{array}$ & Reflux esophagitis 17.3 (80/462) & $23(1-71)^{+}$ \\
\hline
\end{tabular}

PTF, previous treatment failure, FU, follow-up; NA, not available; HM, Heller myotomy.

*Median (interquartile range); ${ }^{\dagger}$ Median (range); ${ }^{\ddagger}$ Previous surgical and endoscopic treatment failure; ${ }^{\S}$ Previous endoscopic treatment failure.

\section{Meta-analysis}

Overall, six studies with 1,548 patients compared the technical success of POEM between achalasia patients with and without previous treatment. The pooled RR for technical success was 1.00 (95\% CI, 0.98 to 1.01 ), $\mathrm{p}=0.56$, Cochran $\mathrm{Q}$ test $\mathrm{p}=0.91, \mathrm{I}^{2}=0 \%$ (Fig. 3). For clinical success, the pooled RR at 1-year follow-up was 0.98 (95\% CI, 0.92 to 1.04 ), $\mathrm{p}=0.46$, Cochran $\mathrm{Q}$ test $\mathrm{p}=0.10, \mathrm{I}^{2}=56 \%$ (Fig. $4 \mathrm{~A}$ ). The results for 2- and 3-year follow-ups were 0.93 (95\% CI, 0.89 to 0.98 ) and 0.89 ( $95 \%$ CI, 0.84 to 0.95 ) (Fig. $4 \mathrm{~B}$ and C). Seven studies with 1,588 patients compared the safety of POEM in achalasia patients with and without previ- ous treatment. The adverse events rate for patients with prior treatment versus treatment naïve patients were $6.3 \%$ and 5.3\%. The pooled RR was 1.17 (95\% CI, 0.78 to 1.76 ), $\mathrm{p}=0.45$, Cochran $\mathrm{Q}$ test $\mathrm{p}=0.60, \mathrm{I}^{2}=0 \%$ (Fig. $5 \mathrm{~A}$ ). There were also no significant difference in major and minor adverse events between the two groups. The RR for major and minor adverse events were 1.14 (95\% CI, 0.71 to 1.82; $\mathrm{p}=0.60)$ and 0.99 (95\% CI, 0.85 to $1.16 ; \mathrm{p}=0.94)$, respectively (Fig. 5B and C). The presence of GERD diagnosed via esophagogastroduodenoscopy (EGD) was documented for 963 patients. The RR for reflux esophagitis at EGD was 1.18 (95\% CI, 0.91 to 1.53), $\mathrm{p}=0.21$, Cochran $\mathrm{Q}$ test $\mathrm{p}=0.51$, 
Table 5. Safety of Peroral Endoscopic Myotomy

\begin{tabular}{|c|c|c|c|c|}
\hline \multirow{2}{*}{ Author } & \multicolumn{2}{|c|}{ Major adverse events } & \multicolumn{2}{|c|}{ Minor adverse events } \\
\hline & PTF & Naïve & PTF & Naïve \\
\hline Tyberg et $a .^{16}$ & 0 & - & 8 Bleeding & - \\
\hline Tyberg et al. ${ }^{21}$ & 2 Mediastinitis & - & 6 Mucosal defects & - \\
\hline Onimaru et al. ${ }^{25}$ & 0 & - & 0 & - \\
\hline Vigneswaran et al. $^{26}$ & $\begin{array}{l}1 \text { Esophageal leak and mediastinal ab- } \\
\text { scess }\end{array}$ & - & 0 & - \\
\hline Zhou et al. ${ }^{28}$ & $\begin{array}{l}1 \text { Pneumothorax } \\
1 \text { Pneumoperitoneum }\end{array}$ & - & $\begin{array}{l}1 \text { Mucosal } \\
\text { perforation }\end{array}$ & - \\
\hline Ling et al. ${ }^{17}$ & 0 & 0 & 0 & 0 \\
\hline $\begin{array}{l}\text { Ngamruengphong } \\
\text { et al. }^{18}\end{array}$ & $\begin{array}{l}1 \text { Pneumonia } \\
1 \text { Mediastinitis } \\
5 \text { Symptomatic pneumoperitoneum } \\
1 \text { Symptomatic pneumothorax } \\
1 \text { Symptomatic subcutaneous emphy- } \\
\text { sema } \\
1 \text { Pleural effusion requiring chest drain }\end{array}$ & - & $\begin{array}{l}7 \text { Mucosotomy } \\
1 \text { Delayed bleeding } \\
1 \text { Submucosal } \\
\text { hematoma }\end{array}$ & - \\
\hline Tang et al. ${ }^{19}$ & 0 & 0 & 1 Bleeding & 2 Bleeding \\
\hline Kristensen et al..$^{20}$ & NA & - & NA & - \\
\hline Orenstein et al. ${ }^{23}$ & $\begin{array}{l}1 \text { Capnoperitoneum alleviated with an- } \\
\text { giocatheter evacuation } \\
1 \text { Mallory-Weiss tear requiring blood } \\
\text { transfusion } \\
1 \text { Mucosal tear requiring a stent }\end{array}$ & $\begin{array}{l}1 \text { Capnoperitoneum alleviated with an- } \\
\text { giocatheter evacuation }\end{array}$ & 0 & $\begin{array}{l}1 \text { Mucosal } \\
\text { tear }\end{array}$ \\
\hline Nabi et al. ${ }^{24}$ & $\begin{array}{l}1 \text { Capnothorax requiring decompression } \\
2 \text { Enlargement of mucosal incision }\end{array}$ & $\begin{array}{l}2 \text { Capnopericardium } \\
1 \text { Capnothorax requiring decompression } \\
1 \text { Enlargement of mucosal incision } \\
130 \text {-Day readmission }\end{array}$ & 11 Mucosal injury & $\begin{array}{l}8 \text { Mucosal } \\
\text { injury }\end{array}$ \\
\hline Sharata et al. ${ }^{27}$ & $\begin{array}{l}1 \text { Bleeding requiring endoscopic re- } \\
\text { intervention } \\
1 \text { Mucosotomy dehiscence needing en- } \\
\text { doscopic suture } \\
1 \text { Capnoperitoneum needed Veress } \\
\text { needle decompression }\end{array}$ & $\begin{array}{l}1 \text { Full-thickness esophageal perforation } \\
\text { requring endoscopic and surgical re- } \\
\text { intervention } \\
1 \text { Capnoperitoneum needed Veress } \\
\text { needle decompression }\end{array}$ & 0 & 0 \\
\hline Zhang et al. ${ }^{22}$ & $\begin{array}{l}5 \text { Prolonged stay }>5 \text { day } \\
3 \text { Readmission within } 30 \text { days related to } \\
\text { POEM (1 diarrhea; } 1 \text { bleeding; } 1 \text { fever) }\end{array}$ & - & NA & - \\
\hline Jones et al. ${ }^{29}$ & $\begin{array}{l}4 \text { Pneumoperitoneum needed needle } \\
\text { decompression }\end{array}$ & $\begin{array}{l}12 \text { Pneumoperitoneum needed needle } \\
\text { decompression }\end{array}$ & NA & NA \\
\hline Liu et al. ${ }^{30}$ & $\begin{array}{l}6 \text { Pneumothorax requiring drainage } \\
2 \text { Hydrothorax requiring drainage } \\
1 \text { Delayed mucosa barrier failure } \\
1 \text { Delayed bleeding requiring intervention } \\
\text { or transfusion } \\
1 \text { Other miscellaneous major adverse } \\
\text { event }\end{array}$ & $\begin{array}{l}13 \text { Pneumothorax requiring drainage } \\
4 \text { Hydrothorax requiring drainage } \\
3 \text { Delayed mucosa barrier failure } \\
1 \text { Delayed bleeding requiring intervention } \\
\text { or transfusion } \\
2 \text { Other miscellaneous major adverse } \\
\text { events }\end{array}$ & NA & NA \\
\hline
\end{tabular}

PTF, previous treatment failure; NA, not available; POEM, peroral endoscopic myotomy.

7.21 minutes ( $95 \% \mathrm{CI}, 4.04$ to $10.39 ; \mathrm{p}<0.001, \mathrm{I}^{2}=0 \%$ ) and 0.09 days ( $95 \% \mathrm{CI},-0.53$ to $0.71 ; \mathrm{p}=0.77, \mathrm{I}^{2}=58 \%$ ) (Table 2, Supplementary Fig. 5). Thirteen studies reported the change in the Eckardt score in the cohort with previous intervention. Ten studies evaluated the change in LES pressure after POEM. The mean Eckardt score was significantly decreased by 5.77 points ( $95 \%$ CI, 5.07 to 6.47; $p<0.001$, $\left.\mathrm{I}^{2}=96 \%\right)$ and LES pressure was significantly reduced by 18.3 $\mathrm{mm} \mathrm{Hg}\left(95 \% \mathrm{CI}, 12.73\right.$ to $23.86 ; \mathrm{p}<0.001, \mathrm{I}^{2}=95 \%$ ) (Fig. $6 \mathrm{~A}$ and C, Supplementary Table 2). The mean Eckardt score and LES pressure in patients with prior treatment were $7.25 \pm 0.14$ points and $38.65 \pm 1.28 \mathrm{~mm} \mathrm{Hg}$, respectively. After POEM, these decreased to $1.07 \pm 0.10$ and $16.28 \pm 0.65$, respectively (Fig. 6B and D). When we excluded the studies that did not report the standard deviation. Significant changes in Eckardt score and LES pressure were still found. The overall MDs in Eckardt score and LES pressure were 5.74 (95\% CI, 5.04 to 6.44; $\left.\mathrm{p}<0.001, \mathrm{I}^{2}=90 \%\right)$ and $20.16 \mathrm{~mm}$ 


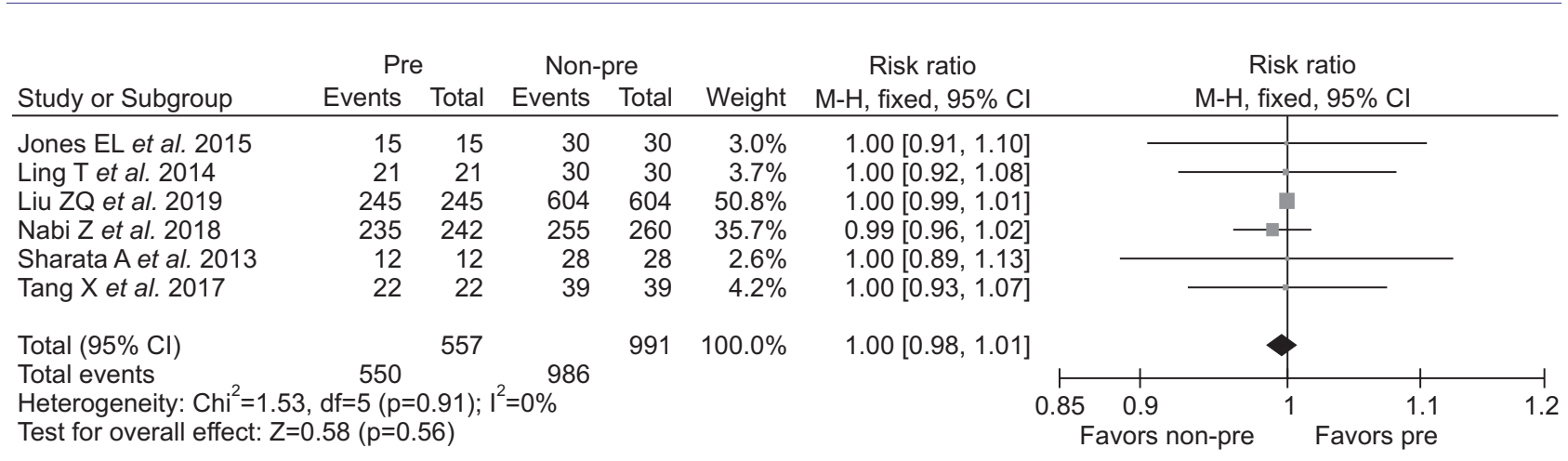

Fig. 3. Meta-analysis of technical success between patients with and without previous intervention(s).

$\mathrm{M}-\mathrm{H}$, Mantel-Haenszel; $\mathrm{Cl}$, confidence interval.

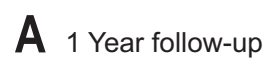

\begin{tabular}{|c|c|c|c|c|c|c|c|c|c|}
\hline \multirow[b]{2}{*}{ Study or Subgroup } & \multicolumn{2}{|c|}{ Pre } & \multicolumn{2}{|c|}{ Non-pre } & \multirow[b]{2}{*}{ Weight } & \multirow{2}{*}{$\begin{array}{l}\text { Risk ratio } \\
\mathrm{M}-\mathrm{H} \text {, random, } 95 \% \mathrm{Cl}\end{array}$} & \multirow{2}{*}{\multicolumn{3}{|c|}{$\begin{array}{l}\text { Risk ratio } \\
\mathrm{M}-\mathrm{H} \text {, random, } 95 \% \mathrm{Cl}\end{array}$}} \\
\hline & Events & Total & Events & Total & & & & & \\
\hline Liu ZQ et al. 2019 & 217 & 245 & 574 & 604 & $45.4 \%$ & $0.93[0.89,0.98]$ & & & \\
\hline Nabi Z et al. 2018 & 145 & 159 & 166 & 183 & $36.8 \%$ & $1.01[0.94,1.07]$ & & & \\
\hline Tang X et al. 2017 & 21 & 22 & 36 & 39 & $17.8 \%$ & $1.03[0.91,1.18]$ & & 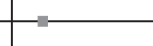 & \\
\hline Total $(95 \% \mathrm{Cl})$ & & 426 & & 826 & $100.0 \%$ & $0.98[0.92,1.04]$ & & & \\
\hline Total events & 383 & & 776 & & & & 4 & & 1 \\
\hline \multicolumn{7}{|c|}{$\begin{array}{l}\text { Heterogeneity: } \mathrm{Tau}^{2}=0.00 ; \mathrm{Chi}^{2}=4.55, \mathrm{df}=2(p=0.10) ; I^{2}=56 \% \\
\text { Test for overall effect: } Z=0.73(p=0.46)\end{array}$} & $\begin{array}{l}0.850 .9 \\
\text { Favors non-pre }\end{array}$ & $\begin{array}{c}1.1 \\
\text { Favors } p\end{array}$ & 1.2 \\
\hline
\end{tabular}

B 2 Years follow-up

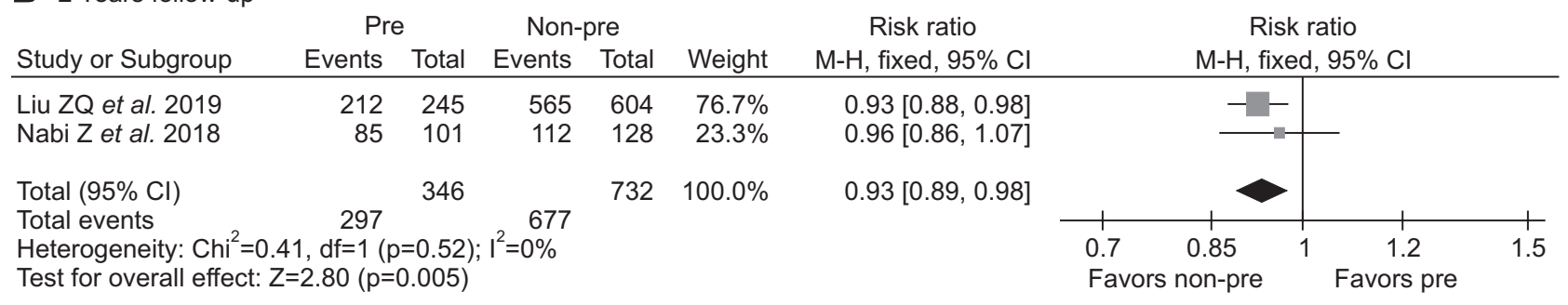

C 3 Years follow-up

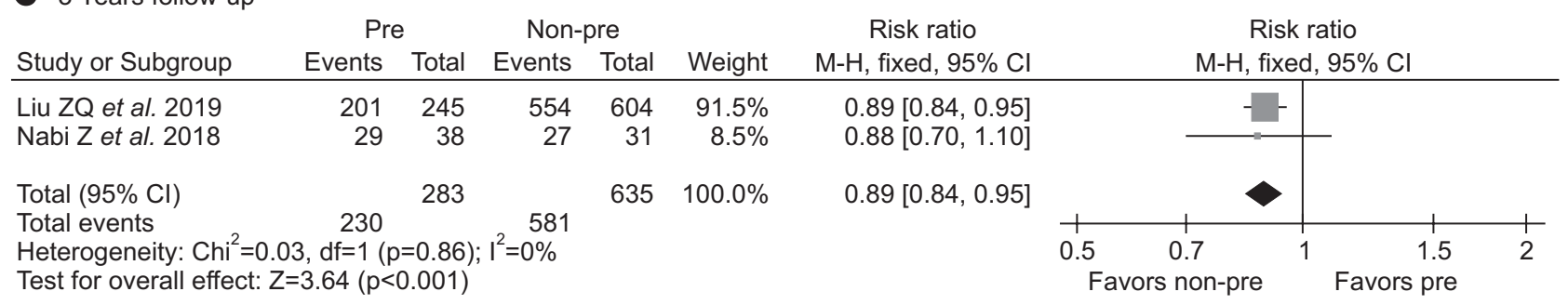

Fig. 4. Meta-analysis of clinical success between patients with and without previous intervention(s). (A) One-year follow-up; (B) 2-year follow-up; (3) 3-year follow-up.

$\mathrm{M}-\mathrm{H}$, Mantel-Haenszel; $\mathrm{Cl}$, confidence interval.

$\mathrm{Hg}$ (95\% CI, 14.76 to $\left.25.56 ; \mathrm{p}<0.001, \mathrm{I}^{2}=87 \%\right)$, respectively.

\section{DISCUSSION}

With the advent of minimally invasive era, POEM has become a promising technique with excellent clinical out- comes for the treatment of achalasia patients with or without failed previous treatment. However, it is technically challenging for several, multifactorial reasons. Irrespective of type of previous intervention for achalasia, endoscopic or surgical, esophageal scarring and fibrosis may result. This may lead to difficulty in delineating tissue planes and reduce the efficacy of submucosal injection, leading to an 
A Overall adverse event

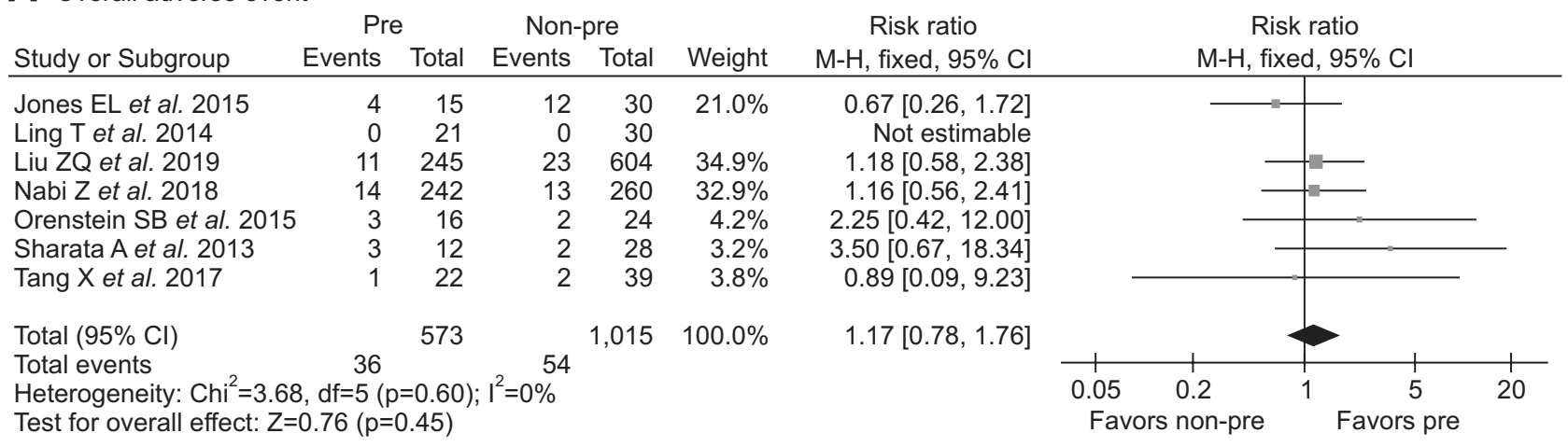

B Major adverse event

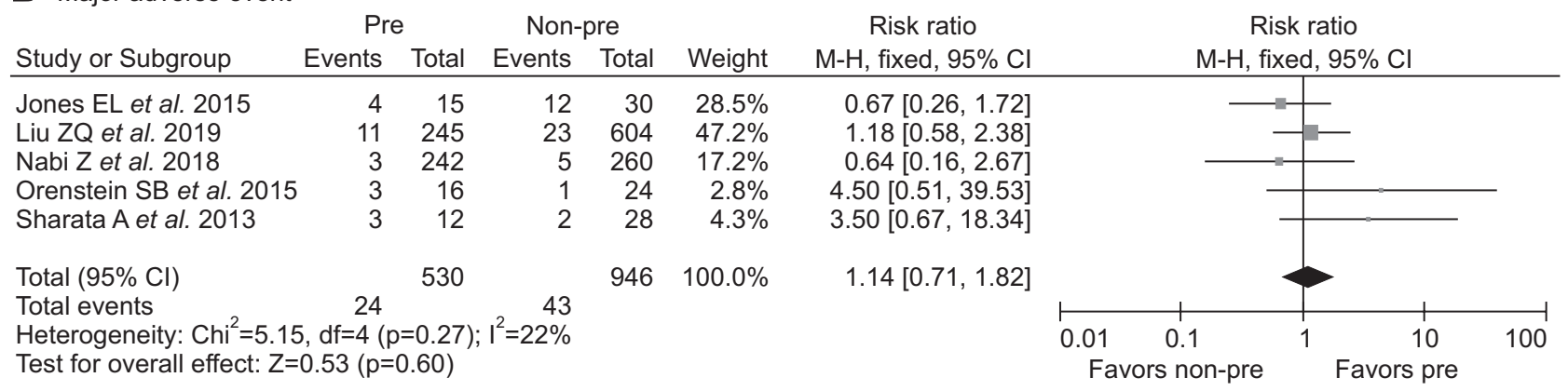

C Minor adverse event

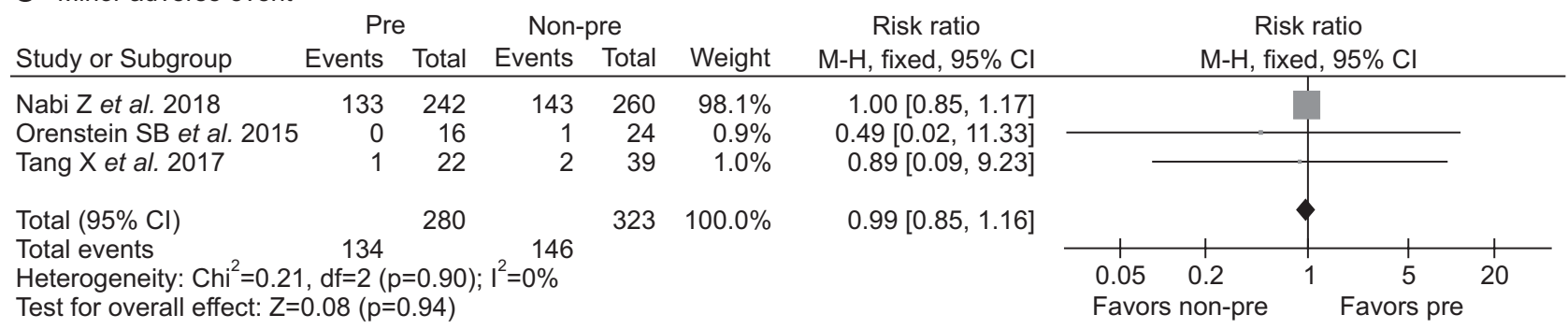

Fig. 5. Meta-analysis of adverse events between patients with and without previous intervention(s). (A) Overall adverse events; (B) major adverse events; (3) minor adverse events.

$\mathrm{M}-\mathrm{H}$, Mantel-Haenszel; $\mathrm{Cl}$, confidence interval.

increased likelihood of complications such as perforation and bleeding. Due to this potentially increased difficulty of POEM after previous interventions for achalasia, we performed this meta-analysis to explore the efficacy and safety of POEM for patients with and without prior treatment. In our present study, we demonstrated that POEM was equally efficacious and safe in achalasia patients with and without previous intervention. We found that POEM achieved high pooled technical (98.0\%) and clinical (90.8\%) success rates and reduced the Eckardt score (MD: 5.77, $\mathrm{p}<0.001$ ) and LES pressure (MD: $18.3 \mathrm{~mm} \mathrm{Hg}, \mathrm{p}<0.001$ ) significantly in patients who have undergone prior treatment. In addition, our meta-analysis demonstrated that the efficacy of POEM in the patients who had undergone prior intervention was comparable to that of the treatment-naive patients. Our result is consistent with several published studies. ${ }^{24,28}$ The favorable results provided by POEM are due to several reasons. POEM is a completely endoscopic and intraluminal approach which is unlikely to be affected by the scars and tissue adhesions resulting from previous treatment. Thus, efficacy is similar to treatment naïve patients. Additionally, POEM provides the opportunity to perform the myotomy in an opposite orientation. Thus, the new myotomy can be performed in a location without scars, resulting in good control of the myotomy length. Conversely, due to the presence of scars, fibrosis and tissue adhesions, the POEM procedure could potentially be more technically challenging, resulting in a longer procedure time and hospital stay. In the Liu et al., ${ }^{30}$ a significantly longer hospital stay after POEM was found in patients with 


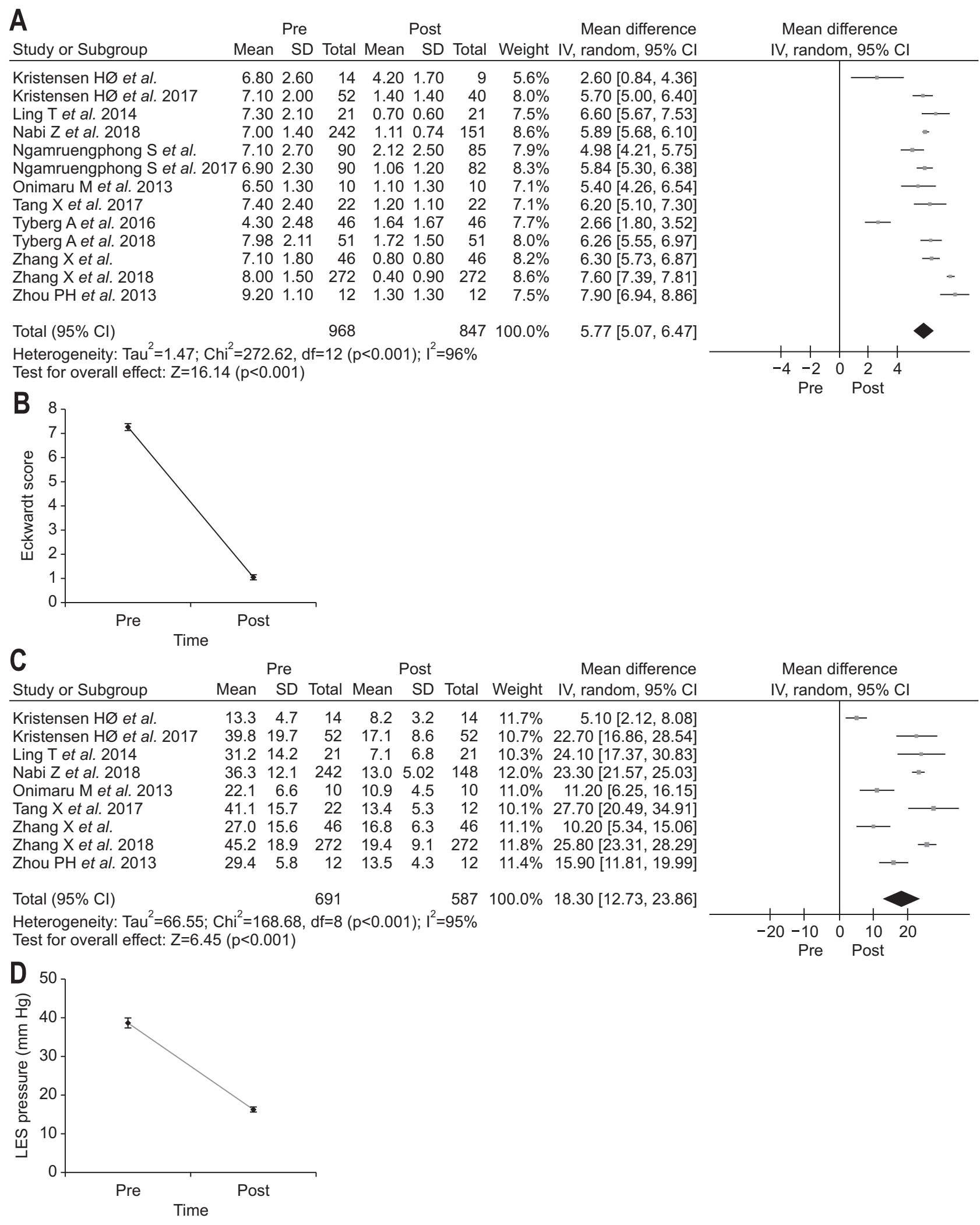

Fig. 6. Changes in the mean Eckardt score and lower esophageal sphincter (LES) pressure before and after peroral endoscopic myotomy (POEM) in patients with previous endoscopic or/and surgical intervention. (A) Change in the mean Eckardt score. (B) Changes in the mean Eckardt score before and after POEM: the diamond corresponds to the mean Eckardt score, and the lines extending from them indicate the standard error above and below the mean. (C) Change in the mean LES pressure. (D) Changes in the mean LES pressure before and after POEM.

$\mathrm{IV}$, inverse variance; $\mathrm{Cl}$, confidence interval. 
prior therapy when compared to the patients without prior treatment ( $<2$ days: $43.7 \%$ vs $53.6 \%$, $\geq 2$ days: $56.3 \%$ vs $46.4 \%, \mathrm{p}=0.001$ ). Our study failed to demonstrate a longer length of hospital stay (MD: 0.09, $\mathrm{p}=0.77$ ) after pooling all related data. Importantly, our analysis was performed with only three studies. In view of this small numbers of studies and sample size, we must interpret this outcome with caution.

When comparing the clinical success rate of POEM in patients with a greater than 2-and 3-year follow-ups, we found that results from the group of treatment naïve patients was superior to the that of the patients who had undergone previous endoscopic or/and surgical interventions. However, an individual study by Nabi et al. ${ }^{24}$ with 502 patients and a greater than 2-year follow-up did not suggest a higher clinical success rate in treatment-naïve patients. Liu et al. ${ }^{30}$ reviewed 849 patients and demonstrated a superior 5-year clinical success rate in the treatment naïve cohort. They indicated that follow-up duration correlated with the difference in clinical failure between patients with and without prior treatment. They also found patients who had undergone more than one previous intervention had a higher risk than those with only one previous treatment. This may be attributed to severe inflammation and fibrosis formed by prior treatments. This difference may also be due to a difference in "symptom-reporting threshold" of patients whose symptoms recurred after prior treatments. Given this discrepancy in outcomes, systematic evaluation of long-term outcomes between the two groups is necessary in the future.

In our study, the most common adverse events related to the POEM procedure in patients with prior treatments were mucosal injury, bleeding, pneumothorax, and pneumoperitoneum. Theoretically, patients who have undergone surgical or/and endoscopic treatment are more prone to incur adverse events because of inflammation and fibrosis. Nevertheless, in the current study, the adverse event rate was not significantly higher in those who had undergone previous interventions when compared to those without interventions. This may be due to all the POEM procedures being performed by experienced operators in our included studies. ${ }^{30}$ When evaluating the GERD rate during follow-ups, we found that the incidence of GERD diagnosed via EGD or questionnaires was not significantly different between the two groups (Supplementary Fig. 4). However, our result may be affected by various factors. For example, the GERD measurement results were only available in a minority of the total patients' number. Additionally, previous fundoplication may have an influence on preventing postoperative reflux. Importantly, there were no procedure-related deaths in any of the included studies.
Our study confirmed the safety of POEM for patients with previous interventions.

To our knowledge, this is the first systematic review and meta-analysis comparing the efficacy and safety of POEM in patients with and without previous treatments. There are a few limitations in the current study. First, only retrospective and prospective studies were included. No randomized controlled studies were found. Second, owing to the paucity of data in the included studies, we were unable to assess the efficacy and safety of POEM for patients with previous surgical or endoscopic interventions separately. Third, some studies included pediatric patients with achalasia and some patients with other esophageal dysmotility disorders. However, these patients accounted for a small percentage and our outcomes were unchanged after removing these studies. Fourth, we were unable to assess the quality of life in patients with prior treatments after POEM due to the limited number of studies reporting this results. Last, long-term (greater than 2 years) differences between the patients with and without prior intervention should be interpreted carefully as only two study reported these outcomes.

\section{CONCLUSION}

POEM appears to be a safe, effective and feasible treatment for those who have undergone previous failed endoscopic or surgical intervention. It has similar outcomes in previously treated and treatment-naïve achalasia patients. It may be an attractive option for the treatment of patients with this difficult condition. However, further studies with a long-term follow-up to determine the durability of rescue POEM are still warranted.

\section{CONFLICTS OF INTEREST}

No potential conflict of interest relevant to this article was reported.

\section{ACKNOWLEDGEMENTS}

This study is independent research funded by the following grants: Medical Science and Technology Plan Projects of Zhejiang Province (No. 2017196257), Youth Foundation of Southwest Medical University (No. 090300031099), Doctoral Research Start-up Funding Project of Affiliated Hospital of Southwest Medical University (No. 16229). 


\section{AUTHOR CONTRIBUTIONS}

Study conception and design: X.T., Y.R. Acquisition of data and critical revision: X.L., J.X. Drafting of manuscript: S.T., C.Z. Revision of manuscript, and final approval of manuscript: X.F., Y.P., X.T.

\section{ORCID}

Shali Tan

Chunyu Zhong

Yutang Ren

Xujuan Luo

Jin $\mathrm{Xu}$

Xiangsheng $\mathrm{Fu}$

Yan Peng

Xiaowei Tang https://orcid.org/0000-0002-8314-9868

https://orcid.org/0000-0002-6934-3795

https://orcid.org/0000-0002-8972-5846

https://orcid.org/0000-0002-3651-8691

https://orcid.org/0000-0001-7005-5865

https://orcid.org/0000-0001-8889-3314

https://orcid.org/0000-0002-4007-0850

https://orcid.org/0000-0001-9947-0720

\section{REFERENCES}

1. Boeckxstaens GE. The lower oesophageal sphincter. Neurogastroenterol Motil 2005;17 Suppl 1:13-21.

2. Moonen A, Annese V, Belmans A, et al. Long-term results of the European achalasia trial: a multicentre randomised controlled trial comparing pneumatic dilation versus laparoscopic Heller myotomy. Gut 2016;65:732-739.

3. Boeckxstaens GE, Annese V, des Varannes SB, et al. Pneumatic dilation versus laparoscopic Heller's myotomy for idiopathic achalasia. N Engl J Med 2011;364:1807-1816.

4. Emami MH, Raisi M, Amini J, et al. Pneumatic balloon dilation therapy is as effective as esophagomyotomy for achalasia. Dysphagia 2008;23:155-160.

5. Kumbhari V, Behary J, Szczesniak M, Zhang T, Cook IJ. Efficacy and safety of pneumatic dilatation for achalasia in the treatment of post-myotomy symptom relapse. Am J Gastroenterol 2013;108:1076-1081.

6. Borges AA, Lemme EM, Abrahao LJ Jr, et al. Pneumatic dilation versus laparoscopic Heller myotomy for the treatment of achalasia: variables related to a good response. Dis Esophagus 2014;27:18-23.

7. Gutschow CA, Töx U, Leers J, Schäfer H, Prenzel KL, Hölscher AH. Botox, dilation, or myotomy? Clinical outcome of interventional and surgical therapies for achalasia. Langenbecks Arch Surg 2010;395:1093-1099.

8. Wang L, Li YM. Recurrent achalasia treated with Heller myotomy: a review of the literature. World J Gastroenterol 2008;14:7122-7126.

9. Horgan S, Hudda K, Eubanks T, McAllister J, Pellegrini CA. Does botulinum toxin injection make esophagomyotomy a more difficult operation? Surg Endosc 1999;13:576-579.

10. Deb S, Deschamps C, Allen MS, et al. Laparoscopic esophageal myotomy for achalasia: factors affecting functional results. Ann Thorac Surg 2005;80:1191-1194.

11. Smith CD, Stival A, Howell DL, Swafford V. Endoscopic therapy for achalasia before Heller myotomy results in worse outcomes than Heller myotomy alone. Ann Surg 2006;243:579-584.

12. Iqbal A, Tierney B, Haider M, et al. Laparoscopic re-operation for failed Heller myotomy. Dis Esophagus 2006;19:193199.

13. Legros L, Ropert A, Brochard C, et al. Long-term results of pneumatic dilatation for relapsing symptoms of achalasia after Heller myotomy. Neurogastroenterol Motil 2014;26:12481255.

14. Rakita S, Villadolid D, Kalipersad C, Thometz D, Rosemurgy A. Outcomes promote reoperative Heller myotomy for symptoms of achalasia. Surg Endosc 2007;21:1709-1714.

15. Gockel I, Junginger T, Bernhard G, Eckardt VF. Heller myotomy for failed pneumatic dilation in achalasia: how effective is it? Ann Surg 2004;239:371-377.

16. Tyberg A, Seewald S, Sharaiha RZ, et al. A multicenter international registry of redo per-oral endoscopic myotomy (POEM) after failed POEM. Gastrointest Endosc 2017;85:1208-1211.

17. Ling T, Guo H, Zou X. Effect of peroral endoscopic myotomy in achalasia patients with failure of prior pneumatic dilation: a prospective case-control study. J Gastroenterol Hepatol 2014;29:1609-1613.

18. Ngamruengphong $\mathrm{S}$, Inoue $\mathrm{H}$, Ujiki $\mathrm{MB}$, et al. Efficacy and safety of peroral endoscopic myotomy for treatment of achalasia after failed Heller myotomy. Clin Gastroenterol Hepatol 2017;15:1531-1537.

19. Tang X, Gong W, Deng Z, et al. Feasibility and safety of peroral endoscopic myotomy for achalasia after failed endoscopic interventions. Dis Esophagus 2017;30:1-6.

20. Kristensen HØ, Kirkegård J, Kjær DW, Mortensen FV, Kunda R, Bjerregaard NC. Long-term outcome of peroral endoscopic myotomy for esophageal achalasia in patients with previous Heller myotomy. Surg Endosc 2017;31:25962601.

21. Tyberg A, Sharaiha RZ, Familiari P, et al. Peroral endoscopic myotomy as salvation technique post-Heller: international experience. Dig Endosc 2018;30:52-56.

22. Zhang X, Modayil RJ, Friedel D, et al. Per-oral endoscopic myotomy in patients with or without prior Heller's myotomy: comparing long-term outcomes in a large U.S. single-center cohort (with videos). Gastrointest Endosc 2018;87:972-985.

23. Orenstein SB, Raigani S, Wu YV, et al. Peroral endoscopic myotomy (POEM) leads to similarresults in patients with and without prior endoscopic or surgical therapy. Surg En- 
dosc 2015;29:1064-1070.

24. Nabi Z, Ramchandani M, Chavan R, et al. Peroral endoscopic myotomy in treatment-naïve achalasia patients versus prior treatment failure cases. Endoscopy 2018;50:358-370.

25. Onimaru $\mathrm{M}$, Inoue $\mathrm{H}$, Ikeda $\mathrm{H}$, et al. Peroral endoscopic myotomy is a viable option for failed surgical esophagocardiomyotomy instead of redo surgical Heller myotomy: a single center prospective study. J Am Coll Surg 2013;217:598-605.

26. Vigneswaran Y, Yetasook AK, Zhao JC, Denham W, Linn JG, Ujiki MB. Peroral endoscopic myotomy (POEM): feasible as reoperation following Heller myotomy. J Gastrointest Surg 2014;18:1071-1076.

27. Sharata A, Kurian AA, Dunst CM, Bhayani NH, Reavis KM, Swanström LL. Peroral endoscopic myotomy (POEM) is safe and effective in the setting of prior endoscopic intervention. J Gastrointest Surg 2013;17:1188-1192.

28. Zhou PH, Li QL, Yao LQ, et al. Peroral endoscopic remyotomy for failed Heller myotomy: a prospective single-center study. Endoscopy 2013;45:161-166.

29. Jones EL, Meara MP, Pittman MR, Hazey JW, Perry KA.
Prior treatment does not influence the performance or early outcome of per-oral endoscopic myotomy for achalasia. Surg Endosc 2016;30:1282-1286.

30. Liu ZQ, Li QL, Chen WF, et al. The effect of prior treatment on clinical outcomes in patients with achalasia undergoing peroral endoscopic myotomy. Endoscopy 2019;51:307-316.

31. Moher D, Liberati A, Tetzlaff J, Altman DG; PRISMA Group. Preferred reporting items for systematic reviews and metaanalyses: the PRISMA statement. Int J Surg 2010;8:336-341.

32. Stang A. Critical evaluation of the Newcastle-Ottawa scale for the assessment of the quality of nonrandomized studies in meta-analyses. Eur J Epidemiol 2010;25:603-605.

33. Wells GA, Shea BJ, O'Connell D, et al. The Newcastle-Ottawa Scale (NOS) for assessing the quality of non-randomized studies in meta-analysis. Ottawa: Ottawa Hospital Research Institute, 2014.

34. NOSCAR POEM White Paper Committee, Stavropoulos SN, Desilets DJ, et al. Per-oral endoscopic myotomy white paper summary. Gastrointest Endosc 2014;80:1-15. 